\title{
A single Mediterranean, possibly Jewish, origin for the Val59Gly CDKN2A mutation in four melanoma- prone families
}

Emanuel Yakobson ${ }^{1}$, Shlomit Eisenberg ${ }^{2}$, Ruth Isacson ${ }^{3}$, David Halle ${ }^{4}$, Efrat Levy-Lahad ${ }^{2}$, Raphael Catane ${ }^{3}$, Mark Safro ${ }^{5}$, Vladimir Sobolev ${ }^{6}$, Thomas Huot ${ }^{7}$, Gordon Peters ${ }^{7}$, Anna Ruiz $^{8}$, Josep Malvehy ${ }^{8}$, Suzana Puig ${ }^{8}$, Agnes Chompret ${ }^{9}$, Marie-Fracoise Avril ${ }^{10}$, Raphael Shafir $^{11}$, Hava Peretz ${ }^{*, 1}$ and Brigitte Bressac-de Paillerets ${ }^{12}$

${ }^{1}$ Clinical Biochemistry Laboratory, Tel Aviv Sourasky Medical Center, Tel Aviv 64239, Israel; ${ }^{2}$ Genetics Institute, Sha'arei Zedek Medical Center, Jerusalem; ${ }^{3}$ Oncology Department, Sha'arei Zedek Medical Center, Jerusalem; ${ }^{4}$ Cancer Cell Biology Laboratory, Sha'arei Zedek Medical Center, Jerusalem; ${ }^{5}$ Department of Structural Biology, Weizmann Institute of Science, Rehovot, Israel; ${ }^{6}$ Department of Plant Sciences, Weizmann Institute of Science, Rehovot, Israel; ${ }^{7}$ Imperial Cancer Research Fund, London, UK; ${ }^{8}$ Barcelona Hospital Clinic, Spain; ${ }^{9}$ Department of Medicine, Institute Gustave Roussy, Villejuif, France; ${ }^{10}$ Dermatology Service, Institute Gustave Roussy, Villejuif, France; ${ }^{11}$ Plastic Surgery Department, Tel Aviv Sourasky Medical Center, Tel Aviv 64239, Israel; ${ }^{12}$ Genetic Service, Institute Gustave Roussy, Villejuif, France

We have screened for CDKN2A germline mutations in 49 Jewish families with two or more cases of melanoma. The Val59Gly mutation, one of the three different alterations identified among these families, was also detected independently in two kindreds from France and one from Spain. The impact of the Val59Gly substitution on the function of the cyclin-dependent kinase inhibitor $\mathrm{p} 16^{\mathrm{INK} 4 \mathrm{a}}$, a product of the CDKN2A gene, was assessed by protein-protein interaction and cell proliferation assays and related to potential structural alterations predicted by molecular modeling. Seven microsatellite markers in the vicinity of the CDKN2A gene were used to determine whether the mutation in these families is identical by descent, or represents a mutational hotspot in the CDKN2A gene. Our results show that the Val59Gly substitution impairs $\mathrm{p} 16^{\mathrm{INK} 4 \mathrm{a}}$ function, and this dysfunction is consistent with structural predictions. All melanoma-affected individuals tested in the families under study harbor this mutation. Interestingly, the Israeli pedigree includes an affected individual who is homozygous for the Val59Gly mutation. A common haplotype of microsatellite markers has been demonstrated for mutation carriers in all four pedigrees. The Israeli pedigree and one of the French melanoma families are of Moroccan and Tunisian Jewish descent, respectively, and the other families originate from regions of France and Spain close to the Pyrenees. We conclude that the Val59Gly mutation is a major contributor to melanoma risk in the families under study and that it may derive from a single ancestral founder of Mediterranean (possibly Jewish) origin. European Journal of Human Genetics (2003) 11, 288-296. doi:10.1038/sj.ejhg.5200961

*Correspondence: Dr H Peretz, Clinical Biochemistry Laboratory, Tel Aviv Sourasky Medical Center, 6 Weizmann str., Tel Aviv 64239, Israel. Tel: +972 3 6973406; Fax: +972 3 6973919;

E-mail: hperetz@tasmc.health.gov.il

Received 3 September 2002; revised 3 January 2003; accepted 3 January 2003 
Keywords: melanoma families; CDKN2A germline mutations; p16 protein structure-function analysis; founder effect; Mediterranean; Jewish origin

\section{Introduction}

About $10 \%$ of melanoma patients come from families in which more than one individual has been affected by the disease. ${ }^{1}$ A substantial proportion of these melanomaprone families show linkage to markers on chromosome 9p21 and most of them harbor a germline mutation in the CDKN2A gene. ${ }^{1,2}$ The CDKN2A gene is unusual in that it encodes two distinct proteins, p16 $6^{\mathrm{INK} 4 \mathrm{a}}$ and $\mathrm{p} 14^{\mathrm{ARF}}$, by exploiting different first exons spliced to a common second exon that is translated in alternative reading frames. ${ }^{3}$ The majority of the germline mutations associated with predisposition to malignant melanoma appear to impinge on the $\mathrm{p} 16^{\mathrm{INK} 4 \mathrm{a}}$ product, a 156 amino-acid protein that functions as an inhibitor of the cyclin-dependent kinases CDK4 and CDK6. ${ }^{4}$ In conjunction with their regulatory Dtype cyclins, these kinases orchestrate the passage of eucaryotic cells from quiescence to the so-called restriction point in the G1 phase of the cell cycle. The role of $\mathrm{p} 16^{\mathrm{INK} 4 \mathrm{a}}$ as a tumor suppressor is underscored by its inactivation by diverse mechanisms in a wide variety of human tumors. ${ }^{3}$ In addition to an increased risk of melanoma, the existence of an increased risk of pancreatic cancer in a subset of families has become evident from epidemiological studies. ${ }^{5-10}$ An excess of breast cancer has also been described in two sets of families of Italian and Swedish origin. ${ }^{9,10}$ Dual predisposition to melanoma and neural system tumours was found associated with germline deletions on 9p21 chromosomal region containing sequences coding for $\mathrm{p} 16^{\mathrm{INK} 4 \mathrm{a}}$ and $\mathrm{p} 14^{\mathrm{ARF}}$ or for $\mathrm{p} 14^{\mathrm{ARF}}$ only. ${ }^{11,12}$

The search for mutations of the CDKN2A gene in numerous familial studies around the world (from America, Australia and Europe) shows that the frequency of CDKN2A mutations is about $20 \%$ on average but varies from 5 to $50 \%$ depending on the criteria for family selection. ${ }^{2,7-10,13-20}$ Most CDKN2A mutations are missense mutations scattered throughout the coding sequences of exons $1 \alpha$ and 2, but there are also small intragenic insertions and deletions. ${ }^{3}$ Several recurrent mutations present in melanoma-prone families from different continents have been shown to be founder mutations. Such are the Met53Ile mutation, ${ }^{21}$ the $19 \mathrm{bp}$ deletion in exon $2^{22}$ and the most common mutation to date, Gly101Trp substitution, described in more than 30 families and sporadic multiple primary melanoma cases, mainly from Italy, France, the US and Spain. ${ }^{23,24}$ Recently, a new recurrent mutation, CDKN2A Val59Gly, was found in four different families: one Israeli of Moroccan Jewish ancestry, two French (one of Tunisian Jewish ancestry and another without known Jewish roots) and a Spanish melanoma pedigree. ${ }^{18,19,25}$ In this report, we provide evidence for functional impairment, association with the disease phenotype and a single genetic origin of the Val59Gly mutation.

\section{Materials and methods Melanoma families}

Melanoma families under study were recruited in Israel, France and Spain as previously described. ${ }^{18-20}$

\section{Mutation detection}

Mutation detection by PCR-single strand polymorphism conformation (PCR-SSCP) analysis and direct DNA sequencing was carried out as previously described. ${ }^{20}$ Genomic DNA was extracted from whole-blood samples and DNA fragments containing p16 gene exon 1, exon 2 (fragments $2 \mathrm{~A}, 2 \mathrm{~B}$ and $2 \mathrm{C}$ ) and exon 3 , with respective intron/exon junctions and the untranslated 3 ' portion were amplified using ${ }^{33} \mathrm{P}$ labeled nucleotides, and electrophoretically separated for SSCP analysis. Variant SSCP bands were purified, reamplified and sequenced. Sequence alterations were confirmed by restriction analysis.

\section{Molecular modeling}

The impact of the Val59Gly substitution on the 3D structure of p16 protein was evaluated as described by us earlier. ${ }^{20}$ Ribbon model of $\mathrm{p} 16^{\mathrm{INK} 4 \mathrm{a}}$ was drawn using the RIBBON 2.5 program. The possible effect of the Val59Gly mutation on p16-CDK4/6 interaction was carried out as described by Sobolev et $\mathrm{al}^{26}$ based on p16-CDK6 complex $3 \mathrm{D}$ data obtained earlier. ${ }^{27,28}$ Ribbon model of p16 in a complex with Cdk6 was prepared using Insight II software (MSI products, CA, USA).

\section{Functional analysis of the Val59Gly substitution}

Functional analysis of the Val59Gly p16 protein substitution was carried out as described by Ruas et $a l^{29}$ and Yakobson et $a l^{20}$ and in legends to Figures $2 \mathrm{a}-\mathrm{d}$. In short, the CDK-binding properties of the Val59Gly p16 variant in vitro was studied by mixing in vitro translated ${ }^{35} \mathrm{~S}$ methionine-labeled CDK2, CDK4 and CDK6 with in vitro translated ${ }^{35} \mathrm{~S}$ methionine-labeled p16 proteins followed by immunoprecipitation with antiserum against full-length p16 ${ }^{\text {INK4a }}$ and analysis of the precipitated proteins by SDSPAGE. Interaction of $\mathrm{p} 16^{\mathrm{INK} 4 \mathrm{a}}$ variants with endogenous CDK4 and CDK6 was studied in human diploid fibroblasts. TIG-er cells (42 PDs) were infected with recombinant 
ecotropic retroviruses encoding 2HA (hemagglutinin)tagged $\mathrm{p} 16^{\mathrm{INK} 4 \mathrm{a}}$ variants, and lysates of the infected cells were used for immunoprecipitation with antibodies against CDK4 or against CDK6. Immunoprecipitated proteins were separated by SDS-PAGE and immunoblotted with antibody against the amino-terminal region of p $16^{\text {INK4a }}$. The impact of the Val59Gly p $16^{\text {INK4a }}$ variant on proliferation of human diploid fibroblasts was evaluated by infecting TIG-er cells with recombinant retroviruses, as above, and 7 days after selection, cells were transferred into 24-well plates and followed for 10 days. For each time point, cells were fixed in 10\% formaldehyde and viable cells stained with crystal violet. Relative numbers of cells were determined by measurements of the optical density at $590 \mathrm{~nm}$.

\section{Microsatellite marker analysis}

Sequences of the forward and reverse primers for the D9S162, D9S1749, D9S974, D9S942, D9S1748, D9S1604 and D9S171 microsatellite markers were obtained from GenBank Database. PCR reactions using genomic DNA of individuals from all four melanoma families were performed as described. ${ }^{20}$ PCR products were separated on $6 \%$ polyacrylamide-urea sequencing gels and visualized by autoradiography. Microsatellite alleles observed in the tested panel of DNA samples were arbitrarily numbered starting with the band of highest molecular weight.

\section{Results}

Structural and functional characterization of the Val59Gly mutation

We have used molecular modeling to predict the likely impact of $\mathrm{p} 16^{\mathrm{INK} 4 \mathrm{a}}$ mutations on its functional interactions with CDK4 and CDK6, based on the published crystal structure of the p16-CDK6 complex. ${ }^{27,28}$ Val59 occupies a position in the hydrophobic core of $\mathrm{p} 16^{\mathrm{INK} 4 \mathrm{a}}$ second ankyrin repeat (Figure 1a). Our analysis suggests that substitution of Gly at this position will induce a distortion of the canonical conformation of the alpha-helix ${ }^{30}$ and a disruption of the hydrophobic interface formed by Val25, Val28, Leu31, Leu32, Val59, Ala60, Leu62 and Leu63. These two factors, the low tendency of Gly residues to be part of an alpha-helix and the distortion of the hydrophobic core, are likely to have a pronounced effect on the general folding of $\mathrm{p} 16^{\mathrm{INK} 4 \mathrm{a}}$, including a change in the relative positions of two alpha-helices formed by residues 25-33 and 57-65. This in turn will change and potentially impair the formation of the conserved H-bond network between the first and the second ankyrin repeats of $\mathrm{p} 16^{\mathrm{INK} 4 \mathrm{a}}$ and CDK6 (Figure 1b). Thus, both the stability of the p16 $6^{\mathrm{INK} 4 \mathrm{a}}$ molecule and its binding to CDK6 will apparently be compromised by the Val59Gly mutation.

To evaluate the functional impact of the Vla59Gly substitution, the $\mathrm{T}$ to $\mathrm{G}$ change was introduced into the

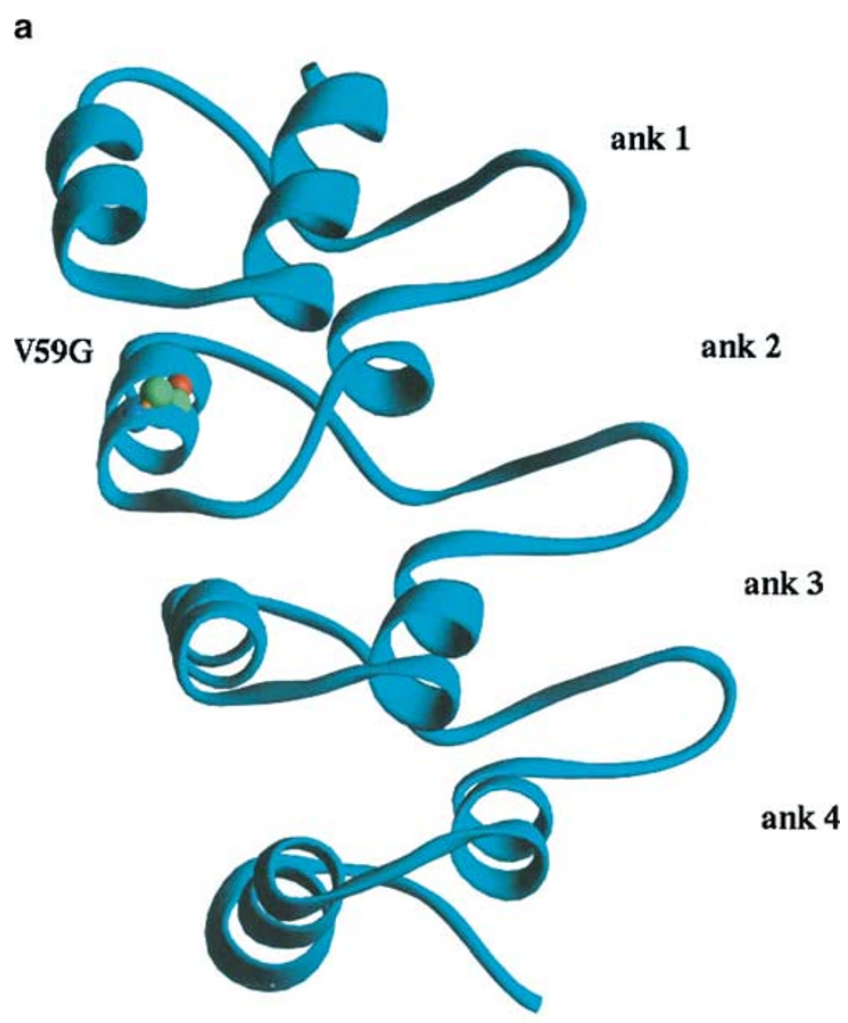

b

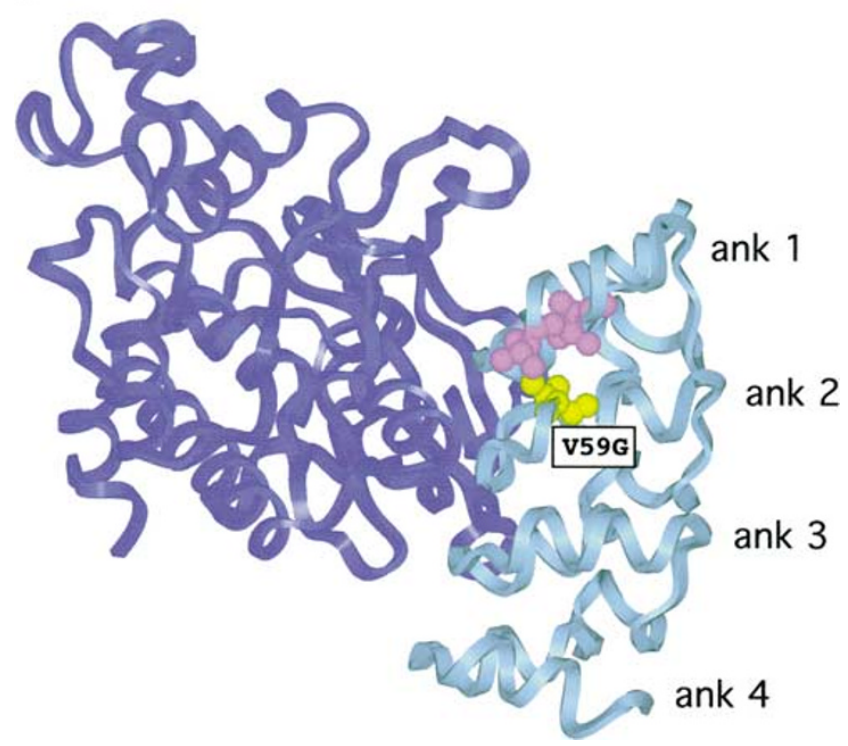

Figure 1 The impact of the Val59Gly substitution on the 3D structure of p16 $16^{\text {NK4a }}$. (a) Ribbon model (blue) of p16 $16^{\text {INK4a }}$ was drawn using the RIBBON 2.5 program. Ankyrin repeats ank1, ank2, ank3 and ank4 are indicated. Gly59 residue at the alpha-helix of the second ankyrin repeat is illustrated in green, blue and red ball and stick. (b) Ribbon model (light blue) of p16 in a complex with Cdk6 (dark blue). Mutated p16 residue Val59 is in yellow ball and stick. Val25 and Val28 residues forming extensive hydrophobic contacts with Val59 are presented as purple ball and stick. The figure was prepared using Insight II software (MSI products, CA, USA). 
a

Load

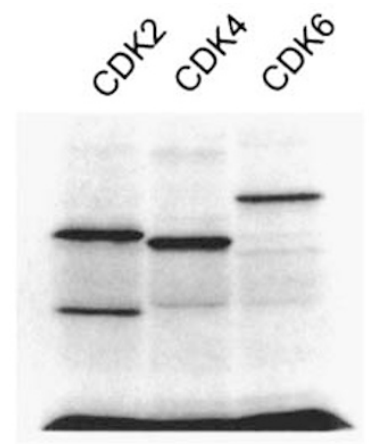

WT

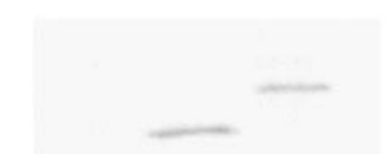

V59G

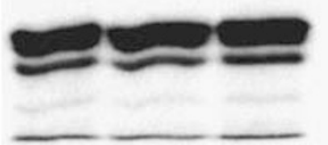

A20P
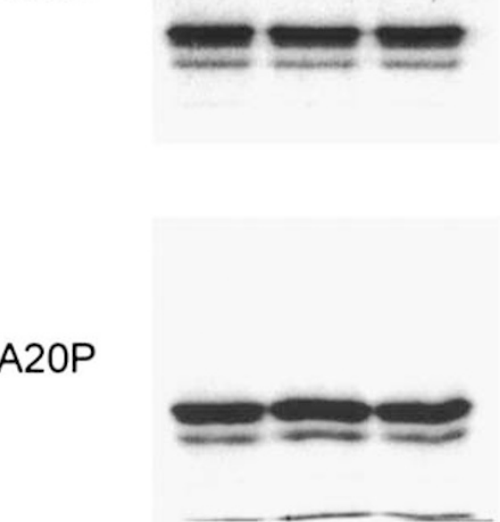

b

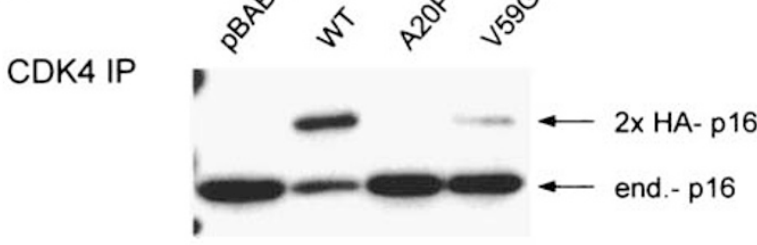

CDK6 IP

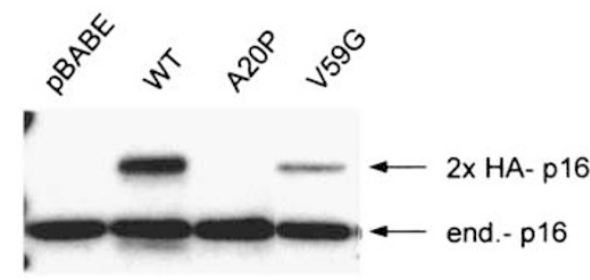

c

Proliferation Assay

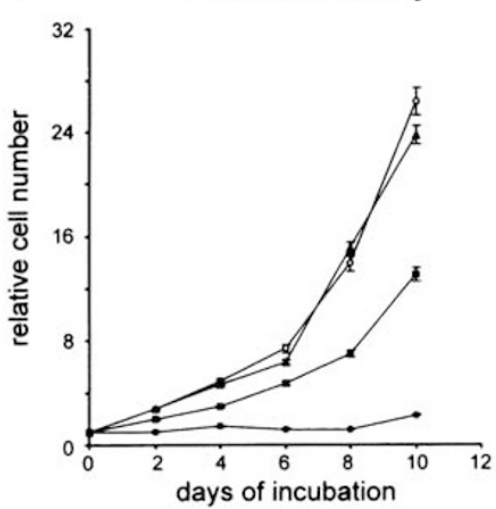

- pbabe(puro)

+ P16 A2OP

$\rightarrow$ p16 V59G

$\rightarrow p 16 \mathrm{Wt}$

Figure 2 The impact of the Val59Gly substitution on the function of the p16 protein. (a) CDK-binding properties of the Val59Gly p16 variant in vitro. In vitro translated ${ }^{35} \mathrm{~S}$ methionine-labeled CDK2, CDK4 and CDK6 were mixed with the same amount of in vitro translated ${ }^{35} \mathrm{~S}$ methionine-labeled p16 proteins at $30^{\circ} \mathrm{C}$ for $30 \mathrm{~min}$. The mixtures were immunoprecipitated with rabbit serum against full-length $\mathrm{p} 16^{\mathrm{INK} 4 \mathrm{a}}$ and the precipitated proteins analyzed by SDS-PAGE in a $12 \%$ polyacrylamide gel. Labeled proteins were visualized by autoradiography. The positions of CDK2, CDK4 and CDK6 are shown in the upper (Load) panel. In the panels denoted WT and V59G, the positions of His 6 -p16 and CDK4 and CDK6 liberated from the coprecipitates can be seen. Ala20Pro, a previously proven nonbinding mutant of $\mathrm{p} 16^{\mathrm{INK} 4 \mathrm{a}}$, was included in this experiment as a control (A20P panel). (b) Interaction of $116^{\mathrm{INK} 4 a}$ variants with endogenous CDK4 and 'CDK6 in human diploid fibroblasts. TIG-er cells (42 PDs) were infected with recombinant ecotropic retroviruses encoding $2 \mathrm{HA}$-tagged p1 $6^{\mathrm{INK} 4 \mathrm{a}}$ variants and selected in $2.5 \mu \mathrm{g} / \mathrm{ml}$ puromycin. At 7 days after infection, lysates were prepared in NP40 lysis buffer and $300 \mu \mathrm{g}$ protein samples were used for immunoprecipitation with antibodies against CDK4 (H-22, Santa Cruz) or against CDK6 (C-21, Santa Cruz). Immunoprecipitated proteins were separated by SDS-PAGE in a 12\% polyacrylamide gel and immunoblotted with JC8 antibody against the amino-terminal region of p16 ${ }^{\text {INK4a }}$. The positions of exogenous (2 $\times$ HA-p16) and endogenous p16 ${ }^{\text {INK4a }}$ (end-p16) are indicated. (c) Impact of the Val59Gly p16 ${ }^{\text {INK4a }}$ variant on proliferation of human diploid fibroblasts. TIG-er cells were infected with recombinant retroviruses, as above, and 7 days after selection, cells were transferred into 24 -well plates $(5 \times 103$ cells per well) and followed for 10 days. For each time point, cells were fixed in $10 \%$ formaldehyde and viable cells stained with crystal violet. Relative numbers of cells were determined by measurements of the optical density at $590 \mathrm{~nm}$. Each time point was determined in triplicate and the averages plotted. 
cDNA encoding wild-type $\mathrm{p} 16^{\mathrm{INK} 4 \mathrm{a}}$ by site-directed mutagenesis, and the variant protein was tested for its ability to interact with CDK4 and CDK6 in vitro and in vivo. Although the Val59Gly variant retained the ability to bind to CDK4 and CDK6 in vitro (Figure 2a), it appeared to have reduced affinity for both CDK4 and CDK6 when expressed in primary human diploid fibroblasts (HDFs) by retroviral transduction (Figure 2b). Thus, whereas HA-tagged wildtype $\mathrm{p} 16^{\mathrm{INK} 4 \mathrm{a}}$ bound CDKs as efficiently as endogenous p16 $6^{\text {INK4a }}$, as demonstrated by coimmunoprecipitation with antisera against CDK4 or CDK6, the HA-tagged Val59G variant showed markedly reduced binding. Nevertheless, it did retain some capacity to interact with CDKs, in contrast to the more fully impaired variant, Ala20Pro (Figure $2 \mathrm{~b}$ and Ruas et $a l^{29}$ ). A similar conclusion was drawn when these variants were compared for their ability to inhibit the proliferation of the retrovirus-infected HDFs. Whereas wild-type $\mathrm{p} 16^{\mathrm{INK} 4 \mathrm{a}}$ completely blocked proliferation and Ala20Pro had no discernible impact on the growth of the expressing cells, Val59Gly gave an intermediate result (Figure 2c). In summary, based on our previous experience in assaying $\mathrm{p} 16^{\mathrm{INK} 4 \mathrm{a}}$ variants, these results indicate that Val59Gly belongs to the class of $\mathrm{p} 16^{\mathrm{INK} 4 \mathrm{a}}$ mutations with a moderate dysfunction.

Melanoma families carrying the Val59Gly substitution The pedigrees of four melanoma-prone families are depicted in Figure 3. Figure 3a shows the extended Israeli family of Moroccan Jewish origin that formed the impetus for this study. The proband, the female subject designated
8 on the pedigree, was diagnosed with malignant melanoma (MM) on her cheek at the age of 40 years. Her brother, designated 10, developed MM on his chin at the age of 36 years. The parents of the MM-affected individuals were of consanguineous marriage, as were their grandparents. The two individuals who developed $\mathrm{MM}$ at the time of this study were born and raised in Israel, while their parents and others of that generation were born and lived most of their life in Morocco. This Jewish family originates from the Antifa village, near Marakesh, in central Morocco. No other cancers were reported in this family. A total of 11 individuals indicated in Figure $3 \mathrm{a}$ were screened for the presence of the Val59Gly CDKN2A germline mutation. Individuals $1,2,3,7$ and 8 were found to carry the mutation in a heterozygous state. The affected male, designated 10 on the pedigree, was found to carry the same mutation in a homozygous state. His mother, designated 6 , is apparently an obligate carrier. Individuals $4,5,9,11$ and 12 were found to have a wild-type CDKN2A genotype.

Figure $3 \mathrm{~b}$ shows the pedigree of the French melanoma family. This family is of Tunisian-Jewish descent. The proband, the female subject designated 1 in the pedigree, was first diagnosed with MM at the age of 27 years. She had a second primary at age 45 years and was genotyped as a carrier of the Val59Gly mutation. This female subject had dysplastic nevus syndrome, pale phototype I skin and red hair color. Her brother, designated 3, had MM at the age of 36 years. Another brother, designated 2, developed glioblastoma at the age of 62 years, in line with previous
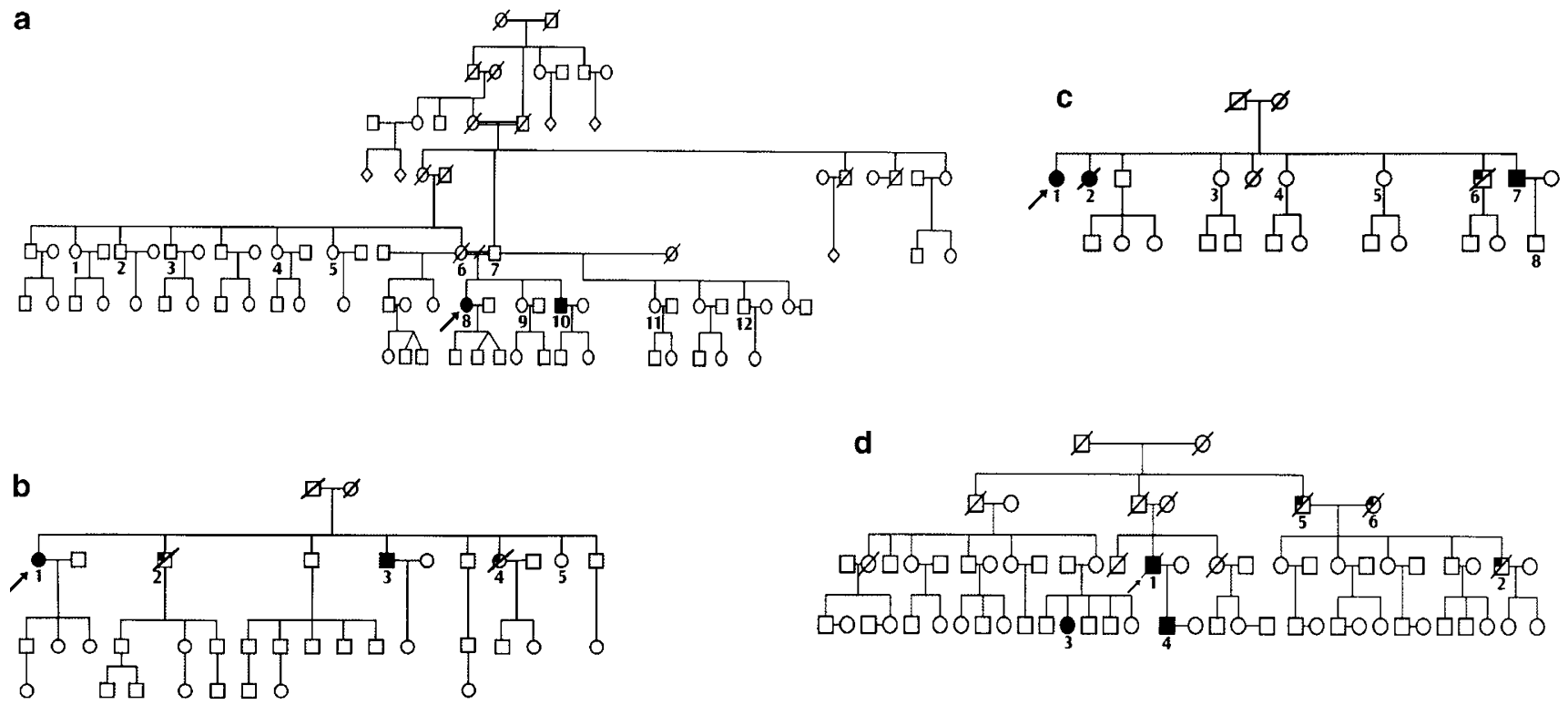

Figure 3 Pedigrees of the Israeli-Moroccan-Jewish Melanoma family (a), the French-Tunisian-Jewish melanoma family (b), the South French-Jewish melanoma family (c) and the Spanish melanoma family (d). Filled squares and circles indicate male and females with confirmed MM, upper quarters filled symbols designate family members afflicted with other cancers. Genotype of individuals and the age of MM onset are indicated in the relevant Results section. 
reports of gliomas being possibly associated with CDKN2A germline mutations. ${ }^{11,12} \mathrm{~A}$ sister of the proband, designated 4 on the pedigree, was afflicted by osteosarcoma at the age of 26 years. The unaffected sister, designated 5 on the pedigree, was tested and found to be a noncarrier of the Val59Gly mutation.

Figure 3c depicts another French melanoma family with three MM-affected individuals. The proband, the female subject designated 1 , developed $\mathrm{MM}$ at the age of 47 years, while her sister, designated 2 , was diagnosed at the age of 35 years. After 2 years later, individual 2 developed lung melanoma metastasis and 2 years after that, brain metastasis. She died at the age of 40 years. Their brother, designated 7 , had three primary melanomas, at ages 45,49 and 51 years, respectively. The individual designated 6 developed lung carcinoma at the age of 43 years, being a moderate smoker. Individuals 1,7 and 8 were identified as Val59Gly mutation carriers, while those designated 3, 4 and 5 were found to have a wild-type CDKN2A genotype. This family comes from the Languedoc-Roussillon region of south-west France, near the Pyrenees mountains, and is not aware of any Jewish ancestry.

Figure 3d shows the Spanish melanoma family with three melanoma-afflicted individuals. The proband, the male designated 1, was first diagnosed with MM at the age of 66 years. He had two more melanoma primaries 10 years later. He also had dysplastic nevus syndrome. This patient died of cardiac pathology at the age of 77 years. The proband's son, designated 4, developed MM at the age of 36 years. A female subject in this pedigree, designated 3, was also affected by MM. Individual 2 had an unidentified neoplasm, individual 5 had colon cancer and squamous cell carcinoma, and individual 6 was reported to have an unidentified neoplasm. The proband was found to carry the Val59Gly mutation, but individual 5, with colon cancer and squamous cell carcinoma, had a wild-type CDKN2A genotype. This Spanish melanoma family has resided for several generations in the Barcelona area, on the southern side of the Pyrenees, and is also not aware of any Jewish ancestry.

\section{Evidence for a single origin of the Val59Gly mutation in the Israeli, French and Spanish families}

To determine whether the mutation in the four apparently unrelated $\mathrm{MM}$ families described here is identical by descent, or represents a mutational hotspot in the CDKN2A gene, we have performed haplotype analysis in mutation carriers identified in these families. Seven microsatellite markers in vicinity of the CDKN2A gene used for this analysis are shown in Figure 4a. Our results indicate that mutation carriers of the Israeli, French and Spanish families possess a common haplotype for the closest four markers, D9S974, D9S942, D9S1748 and D9S1604, to the CDKN2A gene. The data are summarized in Table 1 and Figure $4 \mathrm{~b}$ shows representative data obtained for D9S942 and D9S974.

\section{Discussion}

The impact of the Val59Gly substitution on the structure of p16 ${ }^{\text {INK4a }}$, as deduced by molecular modeling, strongly suggested that both the stability of the $\mathrm{p} 16^{\text {INK4a }}$ molecule and its binding to CDK4 and CDK6 will be compromised by the mutation (Figure 1). The functional analyses indicated that Val59Gly has a moderate effect on the binding of $\mathrm{p} 16^{\mathrm{INK} 4 \mathrm{a}}$ to $\mathrm{CDK} 4$ and CDK6, consistent with the results of the in vivo proliferation assays in human diploid fibroblasts (Figure 2). Although the Val59Gly variant retained the ability to bind to CDK4 and CDK6 in vitro at $30^{\circ} \mathrm{C}$, a more subtle impact on the protein structure, as demonstrated for some temperature-sensitive mutant proteins, ${ }^{29}$ cannot be excluded. Together with the finding that all MM-affected individuals tested harbor the Val59Gly mutation, these results establish the Val59Gly mutation as a major contributor to melanoma risk in the families under study.

A remarkable feature of the Israeli family is that it includes an individual who is homozygous for the Val59Gly mutation. To our knowledge, the only other example of homozygous defect in CDKN2A occurred in the Dutch melanoma kindred with a germline deletion within exon $2 .^{22}$ Both in the Dutch pedigree and in the Moroccan-Jewish pedigree described here, the clinical presentation of the disease in homozygous individuals was not significantly different from those bearing heterozygous germline mutations. Recently, by using primary fibroblasts isolated from a homozygous individual from the Dutch melanoma kindred and a double heterozygous melanoma patient, it was shown that lack of functional $\mathrm{p} 16^{\mathrm{INK} 4 \mathrm{a}}$ but not of $\mathrm{p} 14^{\mathrm{ARF}}$ causes resistance of these cells to oncogenic RAS-induced replication arrest. $^{31,32}$ Fibroblasts and other cell types derived from individuals of the Moroccan-Jewish family, who are homozygous or heterozygous for the Val59Gly mutation, could be of considerable value for further studies on the quantitative role of $\mathrm{p} 16^{\mathrm{INK} 4 \mathrm{a}}$ in sensitivity to transformation, replicative senescence and other aspects of cell physiology relevant to development of malignant tumors.

So far, only four families worldwide were reported to possess the Val59Gly mutation. The Israeli melanoma family represents a large pedigree of Moroccan-Jewish origin. One of the French melanoma families is of Tunisian-Jewish descent. Etymological and historical records provide evidence that Jews with the family names identical to these two families were indeed residing in Morocco in a Jewish community at Fez, dating as early as the 16 th and 17 th centuries. ${ }^{33}$ The other two families, residing on opposite sides of the Pyrenees mountain ridge 

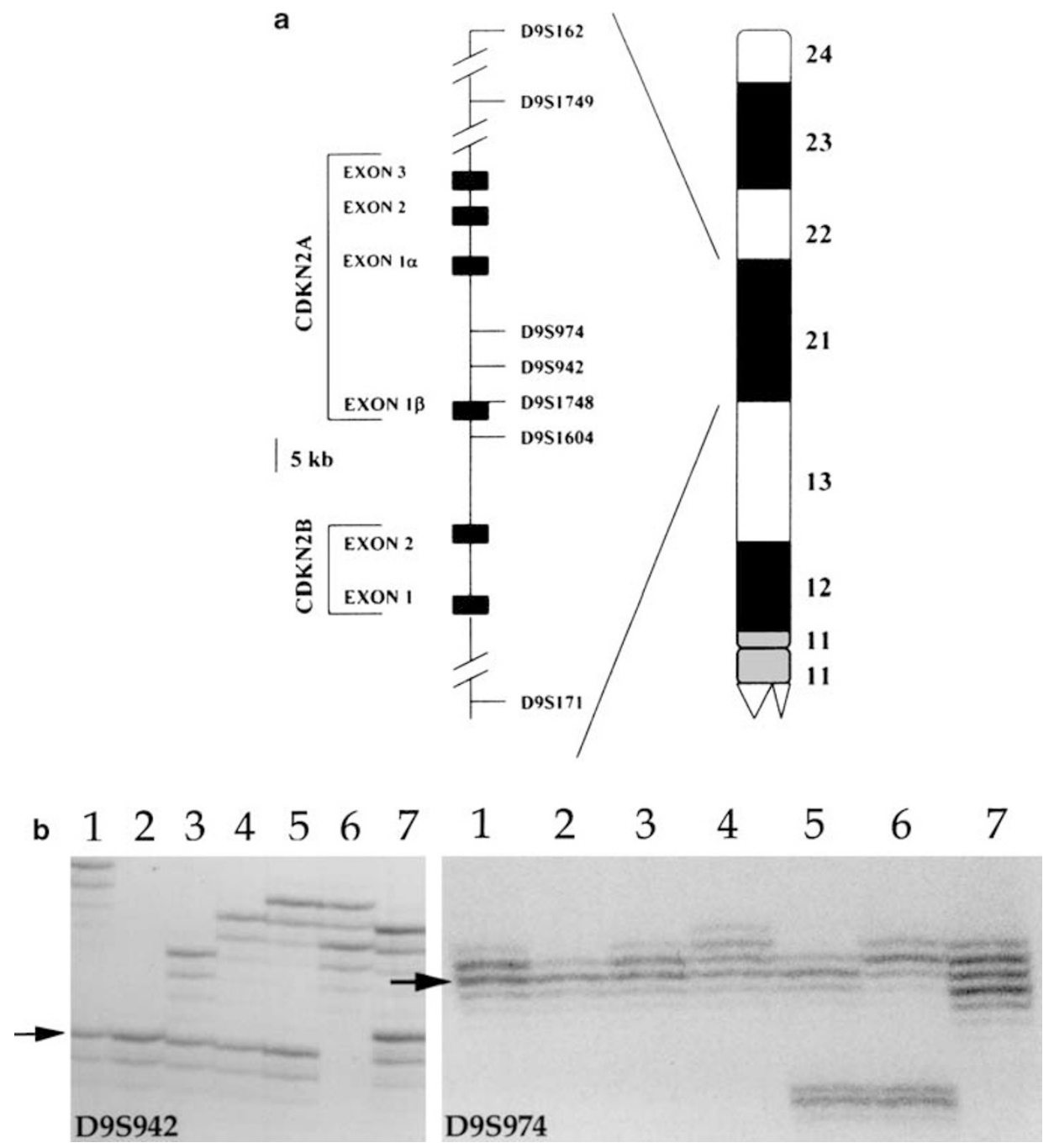

Figure 4 Microsatellite marker analysis. (a) Genetic map of the CDKN2A region on the chromosome 9. Map positions of microsatellite markers D9S162, D9S1749, D9S974, D9S942, D9S1748, D9S1604 and D9S171 are adapted from Ruas and Peters ${ }^{3}$ and Randerson-Moor et al. ${ }^{\prime 2}$ (b) Electrophoretic pattern of D9S942 and D9S974 microsatellite markers resolved on polyacrylamide-urea sequencing gel. Lanes 1 and 2 indicate the MM-affected A8, heterozygote and A10 homozygote individuals, respectively, from the Israeli family; lanes 3 and 4-mutation carrier C7 and C8 individuals, respectively, from the South French melanoma pedigree; lanes 5 and 6-MM affected, B1, and non-affected, B5 sibling from the Tunisian Jewish melanoma pedigree and lane 7 - pattern from a wild-type, control individual. The arrows indicate the common shared allele in all MM-affected individuals.

are unaware of any Jewish ancestry, although strong Jewish communities inhabited these regions as early as the 12th century. If the Jewish origin hypothesis is correct, there are at least two possible explanations for the geographic distribution of the Val59Gly mutation. It may have originated among the Sephardic-Jewish community in Spain before the expulsion of Jews by the Inquisition in year 1495. Alternatively, this mutation may have originated among Jews much earlier, and then migrated with Jews to North Africa, Tunis, Morocco and thereafter to Spain in the period of the Arab conquest of Spain in the 11 th century. ${ }^{34}$ Since many Jews in Spain converted to Christianity in and around the 15th century, it is not surprising to find similar haplotypes in Jewish and nonJewish families 500 years later. Identification of additional families with the Val59Gly mutation and characterization of the associated haplotypes might allow estimation of the age of the Val59Gly mutation with reasonable precision and thus help in establishing its origins. Nevertheless, our results together with that reported previously ${ }^{21-24}$ provide further evidence demonstrating common founders for most of the recurrent mutations in the CDKN2A gene.

The identification of a founder mutation in a defined geographic area, in this case the Mediterranean basin, can provide an opportunity to study disease penetrance, ${ }^{35}$ the 
Table 1 Allele distribution of microsatellite markers in members of the melanoma prone families and an unrelated control DNA.

\begin{tabular}{|c|c|c|c|c|c|c|c|c|}
\hline \multirow[b]{2}{*}{ Marker } & \multicolumn{8}{|c|}{ Genotype } \\
\hline & $A 8^{\mathrm{a}}$ & $A 10$ & B1 & $B 5$ & $C 7$ & C8 & D1 & Control \\
\hline $\begin{array}{l}\text { D9S } 162 \\
\text { D9S } 1749 \\
\text { D9S } 974 \\
\text { D9S } 942 \\
\text { D9S } 1748 \\
\text { D9S } 1604 \\
\text { D9S } 171\end{array}$ & $\begin{array}{ll}2 & 4 \\
9 & 3 \\
2 & 3 \\
1 & 7 \\
2 & 5 \\
1 & 2 \\
2 & 1\end{array}$ & $\begin{array}{ll}4 & 4 \\
2 & 3 \\
3 & 3 \\
7 & 7 \\
5 & 5 \\
2 & 2 \\
1 & 1\end{array}$ & $\begin{array}{ll}3 / 5 \\
5 & 3 \\
5 & 3 \\
2 & 7 \\
3 & 5 \\
2 & 2 \\
2 & 1\end{array}$ & $\begin{array}{ll}1 / 5 & 5 \\
4 / 6 \\
5 & 2 \\
2 & 4 \\
3 & 5 \\
2 & 1 \\
2 & 2\end{array}$ & $\begin{array}{ll}2 & 2 \\
5 & 3 \\
2 & 3 \\
5 & 7 \\
3 & 5 \\
1 & 2 \\
3 & 2\end{array}$ & $\begin{array}{ll}2 & 2 \\
1 & 3 \\
1 & 3 \\
3 & 7 \\
4 & 5 \\
1 & 2 \\
2 & 2\end{array}$ & $\begin{array}{ll}\text { ND } \\
5 & 5 \\
3 & 3 \\
1 & 7 \\
2 & 5 \\
2 & 2 \\
N D\end{array}$ & $\begin{array}{l}\text { ND } \\
7 / 8 \\
2 / 4 \\
3 / 6 \\
1 / 5 \\
1 / 2 \\
\text { ND }\end{array}$ \\
\hline
\end{tabular}

${ }^{a}$ DNA sample designation refers to individuals in the pedigrees presented in Figure 3. The observed alleles were numbered starting with the band of highest molecular weight. See Figure $4 \mathrm{~b}$ illustrating analysis of markers D9S974 and D9S942. ND: not determined. The presumed common haplotype associated with the V59G mutation is shown in bold.

effect of ethnic and genetic background, as well as environmental and lifestyle factors in the development of a malignant disease in the background of the same common genetic susceptibility, and thus facilitate carrier detection and genetic counseling.

\section{Acknowledgements}

This work has been partially supported by Grant 20020077-C from the Israel Cancer Association and by a grant from the Ministry of Health, The Division of Budgeting, Planning \& Pricing, Jerusalem, Israel. EAY was supported by a fellowship from the Israel Cancer Association. Ms Donna Paz Prins from the Genealogy Center of the Beit Hatfutsot Jewish Diaspora Museum, Tel Aviv, was very helpful with etymological and historical searches of the origins of the pedigrees. EAY is grateful to Professor Edward N Trifonov from the Weizmann Institute of Science for his encouragement and for providing facilities for the preparation of the manuscript.

\section{References}

1 Greene MH: The genetics of hereditary melanoma and nevi. 1998 Update. Cancer 1999; 86: 2464-2477.

2 Hussussian CJ, Struewing JP, Goldstein AM et al: Germline p16 mutations in familial melanoma. Nat Genet 1994; 8: 15-21.

3 Ruas M, Peters G: The p16INK4a/CDKN2A tumor suppressor and its relatives. Biochim Biophys Acta 1998; 1378: 115-177.

4 Serrano M, Hannon GJ, Beach D: A new regulatory motif in cellcycle control causing specific inhibition of cyclin D/CDK4. Nature 1993; 366: 704-707.

5 Goldstein AM, Fraser MC, Struewing JP et al: Increased risk of pancreatic cancer in melanoma-prone kindreds with p16 $6^{I N K 4}$ mutations. N Engl J Med 1995; 333: 970-971.

6 Whelan AJ, Bartsch D, Goodfellow PJ: A familial syndrome of pancreatic cancer and melanoma with a mutation in the CDKN2 tumor suppressor gene. N Engl J Med 1995; 333: 975-977.

7 Ciotti P, Strigini P, Bianchi-Scarra G: Familial melanoma and pancreatic cancer. New Engl J Med 1996; 334: 469-470.

8 Vasen HF, Gruis NA, Frants RR, Hille ET, Bergman W: Risk of developing pancreatic cancer in families with familial atypical multiple mole melanoma associated with a specific 19 deletion of p16 (p16-Leiden). Int J Cancer 2000; 87: 809-811.

9 Borg A, Sandberg T, Nilsson K et al: High frequency of multiple melanomas and breast and pancreas carcinomas in CDKN2A mutation-positive melanoma families. J Natl Cancer Inst 2000; 92: 1260-1266.
10 Ghiorzo P, Ciotti P, Mantelli M, et al: Characterization of ligurian melanoma families and risk of occurrence of other neoplasia. Int Cancer 1999; 83: 441-448.

11 Bahuau M, Vidaud D, Jenkins RB et al: Germ-line deletion involving the INK4 locus in familial proneness to melanoma and nervous system tumors. Cancer Res 1998; 58: 2298-2303.

12 Randerson-Moor JA, Harland M, Williams S et al: A germline deletion of p14 ${ }^{\mathrm{ARF}}$ but not CDKN2A in a melanoma-neural system tumour syndrome family. Hum Mol Genet 2001;10: 55-62.

13 Walker GJ, Hussussian CJ, Flores JF et al: Mutations of the CDKN2/p16 INK4 gene in Australian melanoma families. Hum Mol Gen 1995; 4: 1845-1852.

14 Fitzgerald MG, Harkin DP, Silva-Arrieta S: Prevalence of germ-line mutations in p16, p19ARF, and CDK4 in familial melanoma: analysis of a clinic-based population. Proc Natl Acad Sci USA 1996; 93: 8541-8545.

15 Borg A, Johansson U, Johansson O et al: Novel germline mutation in familial malignant melanoma in Southern Sweden. Cancer Res 1996; 56: 2497-2500.

16 Platz A, Hansson J, Mansson-Brahme E et al: Screening of germline mutations in the CDKN2A and CDKN2B genes in Swedish families with hereditary cutaneous melanoma. $J$ Natl Cancer Inst 1997; 8: 697-702.

17 Harland M, Meloni R, Gruis N et al: Germline mutations of the CDNK2 gene in UK melanoma families. Hum Mol Genet 1997; 6: 2061-2067.

18 Soufir N, Avril M-F, Chompret A et al: Prevalence of p16 and CDK4 germline mutations in 48 melanoma-prone families in France. Hum Mol Genet 1998; 7: 209-216.

19 Ruiz A, Puig S, Malvehy J et al: CDKN2A mutations in Spanish cutaneous malignant melanoma families and patients with multiple melanomas and other neoplasia. J Med Genet 1999; 36: 490-493.

20 Yakobson E, Shemesh P, Azizi E et al: Two p16 (CDKN2A) germline mutations in 30 Israeli melanoma families. Eur J Hum Genet 2000; 8: 590-596.

21 Pollock PM, Spurr N, Bishop T et al: Haplotype analysis of two recurrent CDKN2A mutations in 10 melanoma families: evidence for common founders and independent mutations. Hum Mutat 1998; 11: 424-431.

22 Gruis NA, van der Velden PA, Sandkuijl LA et al: Homozygotes for CDKN2A (p16) germline mutation in Dutch familial melanoma kindreds. Nat Genet 1995; 10: 351-353.

23 Ciotti P, Struewing JP, Mantelli M et al: A single genetic origin for the G101W CDKN2A mutation in 20 melanoma-prone families. Am J Hum Genet 2000; 67: 311-319.

24 Auroy S, Avril M-F, Chompret A et al: Sporadic multiple primary melanoma cases: CDKN2A germline mutations with a founder effect. Genes Chromosomes Cancer 2001; 32: 195-202. 
25 Yakobson EA, Eisenberg S, Isakson R et al: Val59Gly CDKN2A (p16) germline mutation may be of Mediterranean (Jewish?) origin. Melanoma Res 2001; 11: S69-S70.

26 Sobolev V, Sorokine A, Prilusky J, Abola EE, Edelman M: Automated analysis of interatomic contacts in proteins. Bioinformatics 1999; 15: 327-332.

27 Russo AA, Tong L, Lee J-O, Jeffrey PD, Pavletich NP: Structural basis for inhibition of the cyclin-dependent kinase CDK6 by the tumour suppressor p16INK4a. Nature 1998; 395: 237-243.

28 Brotherton DH, Dhanaraj V, Wick S et al: Crystal structure of the complex of the cyclin D-dependent kinase CDK6 bound to the cell-cycle inhibitor p19INK4d. Nature 1998; 395: 244-250.

29 Ruas M, Brookes S, McDonald NQ Peters G: Functional evaluation of tumor-specific variants of $\mathrm{p} 16^{\mathrm{INK} 4 \mathrm{a}} / \mathrm{CDKN2A}$ : correlation with protein structure information. Oncogene 1999; 18: 5423-5434.
30 Lewis PN, Go N, Go M, Kotelchuck D, Scheraga HA: Helix probability profiles of denatured proteins and their correlation with native structures. Proc Natl Acad Sci USA 1970; 65: 810-815.

31 Brookes S, Rowe J, Ruas $\mathrm{M}$ et al: INK4a-deficient human diploid fibroblasts are resistant to RAS-induced senescence. EMBO J 2002; 21: 2945.

32 Huot TJ, Rowe J, Harland $\mathrm{M}$ et al: Biallelic mutations in $\mathrm{p} 16^{\mathrm{INK} 4 \mathrm{a}}$ confer resistance to RAS- and Ets-induced senescence in human diploid fibroblasts. Mol Cell Biol 2002; 22: 8135-8143.

33 Jewish Family Names Database, The Jewish Diaspora Museum ("Beit Hatefusolh") Ramat Aviv, Israel.

34 Goodman RM, in Genetic Disorders among the Jewish people. Baltimore, MD: John Hopkins University Press, 1979, pp 1-27.

35 Bishop JA, Wachsmuth RC, Harland M et al: Genotype/phenotype and penetrance studies in melanoma families with germline CDKN2A mutations. J Invest Dermatol 2000; 114: 28-33. 